\title{
Dihydrochalcone glycosides from Oxytropis myriophylla
}

\author{
Gaimei She, Si Wang and Bin Liu*
}

\begin{abstract}
Chemical investigations of the 70\% alcohol extract of Oxytropis myriophylla (Pall.) DC. (Leguminosae) have afforded the new natural product neohesperidin dihydrochalcone (1) and the known phloretin-4'-O- $\beta$-D-glucopyranoside (2), which was the first reported from the genus Oxytropis. This paper reports the isolation and full spectroscopic characterization of compounds $\mathbf{1}$ and $\mathbf{2}$ by NMR, UV, IR and MS data.
\end{abstract}

\section{Background}

Oxytropis is an important genus of the family Leguminosae, also known as "Locoweed". The whole plant of Oxytropis myriophylla (Leguminosae) is an important Mongolian medicine, widely distributed in the southeast and northwest areas of China. It has traditionally been used to treat various diseases of rubella and influenza, applied to swelling and throat pain, together with different types of bleeding. Pharmacological research on this plant showed anti-oxidant and anti-inflammatory properties $[1,2]$. Primary investigation on this plant has led to the isolation of several flavonoids, triterpene glycosides and ligans [3,4], and in a continuation of studies on its minor constituents, the new natural product neohesperidin dihydrochalcone (1) and the known phloridzin (2), the first reported from the genus Oxytropis were obtained. This paper reports the isolation and full spectroscopic characterization of compound $\mathbf{1}$ by NMR, UV, IR and MS data.

\section{Results and Discussion}

The phytochemical study of $70 \%$ ethanol extract obtained from the whole plant of O. myriophylla afforded two compounds, including a new natural product 1 neohesperidin dihydrochalcone and a known metabolite phloretin-4'-O- $\beta$-D-glucopyranoside (2) (Figure 1). The structures of $\mathbf{1}$ and $\mathbf{2}$ were elucidated by detailed spectroscopic analysis and comparison of their spectroscopic data with those reported in the literatures.

\footnotetext{
* Correspondence: liubinyn67@163.com

School of Chinese Pharmacy, Beijing University of Chinese Medicine, Beijing, People's Republic of China
}

Compound 1 was obtained as a white amorphous powder. Its molecular formula was assigned as $\mathrm{C}_{28} \mathrm{H}_{36} \mathrm{O}_{15}$ on the basis of the ${ }^{13} \mathrm{C}$ NMR data and negative HRESIMS $\left(m / z 635.19586[\mathrm{M}+\mathrm{Na}]^{-}\right)$, calcd. for 635.19519. The UV spectrum exhibited absorption maxima at $284 \mathrm{~nm}$ (band II), which were suggestive of a dihydrochalcone skeleton. The IR spectrum of 1 illustrated a broad band at $3374 \mathrm{~cm}^{-1}$ and $1630 \mathrm{~cm}^{-1}$, consistent with the presence of hydroxy group and carbonyl functions. The occurrence of a dihydrochalcone skeleton in the molecule could be easily deduced from the ${ }^{1} \mathrm{H}$ NMR spectrum (Table 1), in which compound 1 showed the signals for an exchangeable proton at $\delta 12.23(1 \mathrm{H}, \mathrm{s}$, H-6'), ABX-type aromatic protons at $\delta\{[6.65 \mathrm{~d}, J=2.0$ $\mathrm{Hz}, \mathrm{H}-2$ ], 6.60 [d, $J=8.0 \mathrm{~Hz}, \mathrm{H}-5$ ], 6.80 [dd, $J=8.0,2.0$ $\mathrm{Hz}, \mathrm{H}-6]\}$ on A-ring, one singlet at high field in the aromatic region $\delta 6.00\left[\mathrm{~s}, \mathrm{H}-3^{\prime}, 5^{\prime}\right]$ on B-ring, together with two mutually coupled methylene groups $[\delta 3.27(2 \mathrm{H}, \mathrm{t}, J$ $=8.2 \mathrm{~Hz}, \mathrm{H}-8)$ and $2.75(2 \mathrm{H}, \mathrm{t}, J=8.2 \mathrm{~Hz}, \mathrm{H}-7]$. These above data suggested the occurrence of a dihydrochalcone skeleton with the A-ring tri-substituted and B-ring penta-substituted in the molecule. In addition, the ${ }^{1} \mathrm{H}$ NMR also exhibited signals due to one $\beta$-glucopyranosyl unit $\left[\delta 5.08\left(\mathrm{~d}, J=7.0 \mathrm{~Hz}, \mathrm{H}-1^{\prime \prime}\right)\right]$. The $J$ value $(7.0$ $\mathrm{xbHz}$ ) of the anomeric proton concluded the $\beta$-configuration of the glucose moiety. These NMR features were resembled to those of compound 2 , phloretin-4'O- $\beta$-D-glucopyranoside [5], except for the existence of an additional set of signals arising from one $\alpha$-L-rhamnopyranosyl $\left[\delta 5.04,\left(1 \mathrm{H}\right.\right.$, br s, $\left.\mathrm{H}-1{ }^{\prime \prime}\right)$ and $1.25(3 \mathrm{H}, \mathrm{d}, J$ $\left.\left.=6.2 \mathrm{~Hz}, \mathrm{H}-6^{\prime \prime \prime}\right)\right]$, a methoxyl groups $[\delta 3.70(3 \mathrm{H}, \mathrm{s})]$ reduced from ${ }^{1} \mathrm{H}$ NMR, ${ }^{13} \mathrm{C}$ NMR and HMQC-TOCSY in 1. In addition, 1, 3, 4-trisubstituted phenyls in A-ring 


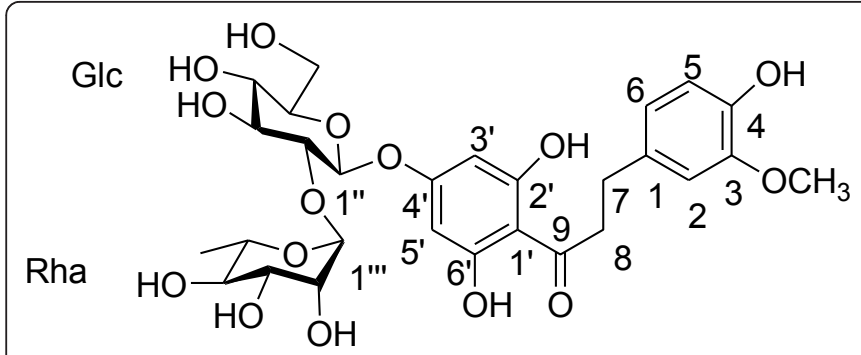<smiles>O=C(CCc1ccc(O)cc1)c1c(O)cc(OC(O)C(O)CO)cc1O</smiles>

Figure 1 Structure of compounds 1 - 2 from 0 . myriophylla.

compound 1, instead of 1, 4-disubstituted aromatic Arings in the above-mentioned glycoside. The attachment of the glucopyranosyl moiety was deduced to be at C-4' according to glycosylation rule. It is observed that the chemical shifts of glucosyl C-2" was downfield shifted to $\delta 77.1$ in $\mathbf{1}$, from $\delta 74.7$ in 2 , suggesting that the $\alpha-\mathrm{L}-$

Table $1{ }^{13} \mathrm{C}(125 \mathrm{MHz})$ and ${ }^{1} \mathrm{H}(500 \mathrm{MHz})$ NMR spectroscopic data for 1 in DMSO- $d_{6}$.

\begin{tabular}{lcl}
\hline position & $\boldsymbol{\delta}_{\mathbf{H}}$ & $\boldsymbol{\delta}_{\mathbf{C}}$ \\
\hline 1 & & 130.4 \\
2 & $6.65(1 \mathrm{H}, \mathrm{d}, J=2.0 \mathrm{~Hz})$ & 115.7 \\
3 & & 146.3 \\
4 & & 145.8 \\
5 & $6.60(1 \mathrm{H}, \mathrm{d}, J=8.0 \mathrm{~Hz})$ & 112.4 \\
6 & $6.80(1 \mathrm{H}, \mathrm{d}, J=8.0 \mathrm{~Hz})$ & 118.7 \\
7 & $2.75(2 \mathrm{H}, \mathrm{t}, J=8.2 \mathrm{~Hz})$ & 29.4 \\
8 & $3.27(2 \mathrm{H}, \mathrm{t}, J=8.2 \mathrm{~Hz})$ & 45.4 \\
9 & & 204.9 \\
$1^{\prime}$ & & 105.3 \\
$2^{\prime}$ & & 162.9 \\
$3^{\prime}$ & & 94.8 \\
$4^{\prime}$ & $6.00(1 \mathrm{H}, \mathrm{s})$ & 163.7 \\
$5^{\prime}$ & & 94.8 \\
$6^{\prime}$ & $6.00(1 \mathrm{H}, \mathrm{s})$ & 162.9 \\
OCH & & 55.7 \\
$1^{\prime \prime}$ & $3.70(3 \mathrm{H}, \mathrm{s})$ & 97.1 \\
$2^{\prime \prime}$ & $5.08(1 \mathrm{H}, \mathrm{d}, J=7.0 \mathrm{~Hz})$ & 77.1 \\
$3^{\prime \prime}$ & 3.50 & 76.5 \\
$4^{\prime \prime}$ & 3.34 & 69.4 \\
$5^{\prime \prime}$ & 3.50 & 76.8 \\
$6^{\prime \prime}$ & 3.37 & 60.3 \\
$1^{\prime \prime \prime}$ & $3.50 \sim 3.65$ & 100.6 \\
$2^{\prime \prime \prime}$ & $5.04(1 \mathrm{H}, \mathrm{br} \mathrm{s})$ & 70.4 \\
$3^{\prime \prime \prime}$ & 3.82 & 71.9 \\
$4^{\prime \prime \prime}$ & 3.02 & 68.3 \\
$5^{\prime \prime \prime}$ & 3.02 & 18.1 \\
$6^{\prime \prime \prime}$ & 3.82 & \\
\hline & $1.25(3 \mathrm{H}, \mathrm{d}, J=7.0 \mathrm{~Hz})$ & \\
\hline
\end{tabular}

rhamnopyranosyl group was located at the glucosyl C-2" in 1. The conclusion was further confirmed by the $\mathrm{HMBC}$ spectrum in which the anomeric proton of the glucopyranosyl moiety at $\delta 5.08(\mathrm{~d}, \mathrm{H}-1$ ") showed long range correlation with $\mathrm{C}\left(4^{\prime}\right)(\delta$ 163.17). Moreover, the other correlations of $\mathrm{H}-\left(\mathrm{OCH}_{3}\right)(\delta 3.70)$ with $\mathrm{C}-3, \mathrm{H}-1$ "' ( $\delta$ 5.04) with C-2", respectively, in the HMBC spectrum confirmed the structure of compound $\mathbf{1}$. Therefore, the structure of 1 was determined to be neohesperidin dihydrochalcone.

In a previous study, the structure of $\mathbf{1}$ as we presented in this paper is an artificial sweetener derived from citrus, which had been synthesized by neohesperidin [6]. The known compound, phloretin-4'-O- $\beta$-D-glucopyranoside (2) was the first reported from the Malus pumila and this compound was found to show insect-antifeedant activity [7]. Particularly worth mentioning is phloretin-4'-O- $\beta$-D-glucopyranoside (2) is bitter, as opposed to the sweetness of $\mathbf{1}$ [6]. The spectral data of 2 are in full agreement with those reported previously. To the best of our knowledge, the full NMR assignments of neohesperidin dihydrochalcone $(\mathbf{1})$ are reported for the first time, on the basis of detailed spectroscopic analysis. And phloretin-4'-O- $\beta$-D-glucopyranoside (2) has not previously been reported from any plant of Oxytropis.

\section{Experimental \\ General}

UV spectra were measured with a UV 210A Shimadzu spectrometer (Shimadzu, Kyoto, Japan). IR spectra were recorded on an IR-450 spectrometer (Shimadzu, Kyoto, Japan). ${ }^{1} \mathrm{H}$ and ${ }^{13} \mathrm{C}$ NMR, HMQC, HMBC, and HMQCTOCSY spectra were performed in pyridine on a Bruker DRX-500 spectrometer $\left(500 \mathrm{MHz}\right.$ for ${ }^{1} \mathrm{H}$, and 125 for $\left.{ }^{13} \mathrm{C}\right)$. ESIMS and HRESIMS were taken on an AutoSpe 3000 spectrometer (VG, Manchester, UK). The macroporous resin AB-8 (pore radius $130 \sim 140 \mathrm{~A}$, Tianjin Haiguang Chemical Factory, Tianjin, China), MCI-gel CHP20P (Mitsubishi Chemical Co., Kyoto, Japan), ODS- 
A (YMC Co. Ltd., Kyoto, Japan), and silica gel (Qingdao Haiyang Chemical Co., Qingdao, China) were used for chromatography.

\section{Plant material}

The whole plant of $O$. myriophylla was collected from Inner Mongolia Province, China, in June 2006, and identified by Prof. Dong Yu in Inner Mongolia Medical College. The voucher specimen (No. 0648209) was deposited with the KUN Herbarium of Kunming Institute of Botany, Chinese Academy of Sciences.

\section{Extraction and Isolation}

The whole plant $(3.0 \mathrm{~kg})$ of O. myriophylla was cut into small pieces and extracted with $70 \% \mathrm{EtOH}$ at refluxed temperature, and then concentrated in vavco to yield a crude extract (256 g). The EtOH crude extract (200 g) was chromatographed on a AB-8 $(10 \times 100 \mathrm{~cm})$ and eluted with $\mathrm{H}_{2} \mathrm{O}: \mathrm{EtOH}(1: 0-0: 1)$ and to give six fractions $(0 \%, 30 \%, 50 \%, 70 \%, 90 \%$ and $100 \% \mathrm{EtOH}$ fractions). The $70 \% \mathrm{EtOH}$ fraction (12 g) was purified by MCI-gel CHP20P and ODS-A eluted with a step gradient of $\mathrm{H}_{2} \mathrm{O}: \mathrm{MeOH}(1: 0-0: 1)$, and silica gel $\left(\mathrm{CHCl}_{3}\right.$ : $\left.\mathrm{MeOH}: \mathrm{H}_{2} \mathrm{O}, 9: 1: 0.1-7: 3: 0.5\right)$, respectively, to give $\mathbf{1}$ (12 $\mathrm{mg}$ ) and $2(27 \mathrm{mg})$.

\section{Authors' contributions}

GS carried out the chemical analysis-structure elucidation and drafted the Manuscript; SW carried out the chemical and biological studies; BL conceived of the study and its design and coordination of the scientific teams. All authors have read and approved the final manuscript.

\section{Competing interests}

The authors declare that they have no competing interests.

Received: 5 September 2011 Accepted: 9 November 2011

Published: 9 November 2011

\section{References}

1. She GM, Sun FF, Lv HN, Liu B: Radical scavenging activity of Oxtropis myriophylla. Chinese Journal of Experimental Traditional Medical Formulae 2010, 16:91-94.

2. Lu JH, Liu Y, Zhao YY, Tu GZ: New flavonoids from Oxytropis myriophylla. Chem Pharm Bull 2004, 52:276-278.

3. She GM, Sun FF, Liu B: Three new flavonoid glycosides from Oxytropis myriophylla. J Nat Med 2011, 65:1-5.

4. She GM, Sun FF, Liu B: A new ligan from Oxytropis myriophylla. Nat Prod Res 2011.

5. El-Naggar SF, El-Feraly FS, Foos JS, Doskotch RW: Flavonoids from the leaves of Kalmia latifolia. J Nat Prod 1980, 43:739-751.

6. Gent JF, Bartoshuk LM: Sweetness of sucrose, neohesperidin dihydrochalcone, and saccharin is related to genetic ability to taste the bitter substance 6-n-propylthiouracil. Chem Senses 1982, 7:265-272.

7. Kubo I, Matsumoto A: Isolation of an insect-antifeedant, phloretin 4'-O- $\beta$ D-glucopyranoside, by rotation locular counter-current chromatography and determination of its preferred conformation in solution by nuclear magnetic resonance analysis. Chem Pharm Bull 1985, 33:3817-3820.

doi:10.1186/1752-153X-5-71

Cite this article as: She et al:: Dihydrochalcone glycosides from Oxytropis myriophylla. Chemistry Central Journal 2011 5:71.

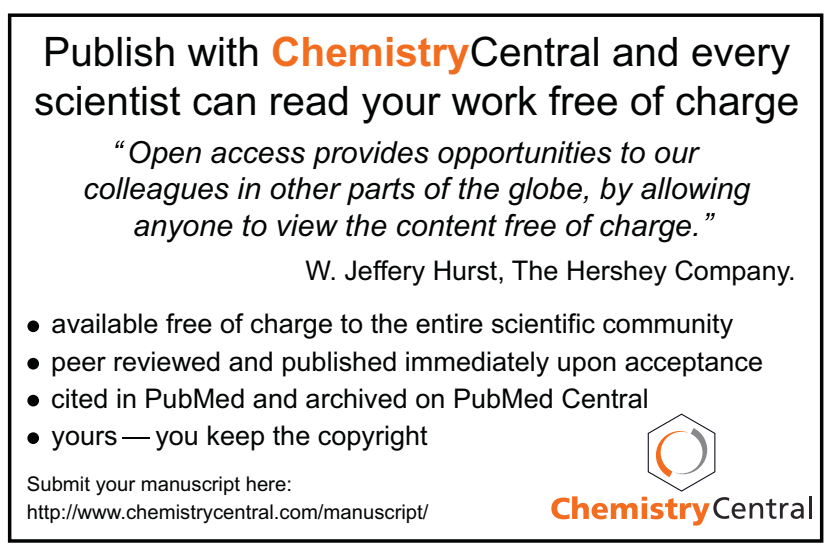

